\title{
Histaminergic Neurons Protect the Developing Hippocampus from Kainic Acid-Induced Neuronal Damage in an Organotypic Coculture System
}

\author{
Tiina-Kaisa Kukko-Lukjanov, ${ }^{1,2}$ Sanna Soini, ${ }^{1}$ Tomi Taira, ${ }^{3}$ Kimmo A. Michelsen, ${ }^{2}$ Pertti Panula,,${ }^{2,4}$ and \\ Irma E. Holopainen ${ }^{1}$ \\ ${ }^{1}$ Department of Pharmacology and Clinical Pharmacology, University of Turku, ${ }^{2}$ Department of Biology, Åbo Akademi University, Biocity, FIN-20520 \\ Turku, Finland, ${ }^{3}$ Neuroscience Center and Department of Biosciences, and ${ }^{4}$ Neuroscience Center, Institute of Biomedicine/Anatomy, FIN-00014 University \\ of Helsinki, Finland
}

The central histaminergic neuron system inhibits epileptic seizures, which is suggested to occur mainly through histamine $1\left(\mathrm{H}_{1}\right)$ and histamine $3\left(\mathrm{H}_{3}\right)$ receptors. However, the importance of histaminergic neurons in seizure-induced cell damage is poorly known. In this study, we used an organotypic coculture system and confocal microscopy to examine whether histaminergic neurons, which were verified by immunohistochemistry, have any protective effect on kainic acid (KA)-induced neuronal damage in the developing hippocampus. Fluoro-Jade B, a specific marker for degenerating neurons, indicated that, after the $12 \mathrm{~h} \mathrm{KA}(5 \mu \mathrm{m})$ treatment, neuronal damage was significantly attenuated in the hippocampus cultured together with the posterior hypothalamic slice containing histaminergic neurons [HI plus HY (POST)] when compared with the hippocampus cultured alone (HI) or with the anterior hypothalamus devoid of histaminergic neurons. Moreover, $\alpha$-fluoromethylhistidine, an inhibitor of histamine synthesis, eliminated the neuroprotective effect in KAtreated HI plus HY (POST), and extracellularly applied histamine ( $1 \mathrm{~nm}$ to $100 \mu \mathrm{M})$ significantly attenuated neuronal damage only at $1 \mathrm{nM}$ concentration in HI. After the $6 \mathrm{~h}$ KA treatment, spontaneous electrical activity registered in the CA1 subregion contained significantly less burst activity in HI plus HY (POST) than in HI. Finally, in KA-treated slices, the $\mathrm{H}_{3}$ receptor antagonist thioperamide enhanced the neuroprotective effect of histaminergic neurons, whereas the $\mathrm{H}_{1}$ receptor antagonists triprolidine and mepyramine dose-dependently decreased the neuroprotection in HI plus HY (POST). Our results suggest that histaminergic neurons protect the developing hippocampus from KA-induced neuronal damage, with regulation of neuronal survival being at least partly mediated through $\mathrm{H}_{1}$ and $\mathrm{H}_{3}$ receptors.

Key words: epilepsy; histamine; monoamine; neurotoxicity; neuroprotection; confocal microscopy

\section{Introduction}

The central histaminergic neurons, located in the tuberomammillary nucleus in the posterior hypothalamus (Watanabe et al., 1983; Panula et al., 1984), have widely distributed projections throughout the brain regulating a broad range of physiological functions such as sleep-wake cycle, energy and endocrine homeostasis, and memory processes (Haas and Panula, 2003).

In different animal models of epileptic seizures, increased brain histamine levels elevate seizure threshold and reduce severity and duration of seizures (Scherkl et al., 1991; Yokoyama et al., 1992; Kamei, 2001; Yawata et al., 2004), whereas decreased histamine levels have the opposite effect (Yokoyama et al., 1992). Moreover, brain histamine levels are significantly lower in the

Received April 8, 2005; revised Dec. 2, 2005; accepted Dec. 5, 2005

This work was supported by funds from the Sigrid Juselius Foundation, the Special State Grant for Clinical Research, the Foundation of the University of Turku, and the Arvo and Lea Ylppö Foundation to I.E.H., as well as funds from the Finnish Cultural Foundation, the Finnish Society of Sciences and Letters and Research, and the Science Foundation of Farmos to T.-K.K.-L. We thank F. Lopez-Picon for technical assistance.

Correspondence should be addressed to Dr. Irma E. Holopainen, Department of Pharmacology and Clinical Pharmacology, University of Turku, Itäinen Pitkäkatu 4, FIN-20520 Turku, Finland. E-mail: irma.holopainen@utu.fi.

DOI:10.1523/JNEUROSCI.1369-05.2006

Copyright $\odot 2006$ Society for Neuroscience $\quad$ 0270-6474/06/261088-10\$15.00/0 genetically epilepsy-prone rats compared with normal rats (Onodera et al., 1992; Midzyanovskaya et al., 2002), which is in accordance with the clinical study in which histamine concentration is decreased in the cerebrospinal fluid of children with febrile convulsions compared with children without seizures (Kiviranta et al., 1995).

Of the four histamine receptors, histamine $1\left(\mathrm{H}_{1}\right)$ and histamine $3\left(\mathrm{H}_{3}\right)$ receptors are suggested to be of importance in decreasing seizure activity. In accordance, the first-generation $\mathrm{H}_{1}$ receptor antagonists have elicited epileptiform activity (Gerald and Richter, 1976; Yokoyama et al., 1996; Kamei et al., 2000; Fujii et al., 2003), controlling its occurrence in particular in the immature brain (Yokoyama, 2001). $\mathrm{H}_{3}$ receptor antagonists, which block the $\mathrm{H}_{3}$ autoreceptor function, are suggested to decrease seizure activity by increasing histamine release (Yokoyama et al., 1993, 1994; Kamei, 2001; Zhang et al., 2003).

Organotypic hippocampal slice cultures are widely used as a model to study neurobiological and pharmacological properties of the hippocampus. In these cultures, synaptic organization, expression of receptors, and intrinsic hippocampal fiber pathways are developed corresponding to their in vivo counterparts (Frotscher et al., 1995; Holopainen and Lauren, 2003). The treat- 
ment of cultures with the glutamate receptor agonist kainic acid (KA) leads to enhanced excitation and region-selective neuronal death (Fisher and Alger, 1984; Bruce et al., 1995; Routbort et al., 1999; Holopainen et al., 2001; Liu et al., 2001), which largely correspond to that detected in the hippocampus of epileptic animals in experimental conditions (Buckmaster and Dudek, 1997; Lynch and Sutula, 2000; Zhang et al., 2002).

Although the inhibitory effect of histamine on seizures is well documented, it is not known whether or not histaminergic neurons have any protective effect in seizure-induced neuronal damage in the immature brain. In the present study, we used an in vitro model of enhanced excitation in which epileptiform activity and neuronal damage was induced by KA. In addition to using the conventional hippocampal organotypic slice culture system, we set up an additional coculture method in which a hippocampal slice was cultured together with a posterior hypothalamic slice containing histaminergic neurons. The novel results of our study indicate that histaminergic innervation can protect the pyramidal $\mathrm{CA} 3 \mathrm{a} / \mathrm{b}$ neurons from KA-induced neuronal damage in the developing hippocampus, the neuroprotective effect being mediated through $\mathrm{H}_{1}$ and $\mathrm{H}_{3}$ receptors.

\section{Materials and Methods}

Organotypic slice culture systems. Three different organotypic slice culture systems were used in this study. The first culture system consisted of a hippocampal slice, which was cultured alone (HI). In the second culture system, a hippocampal slice was cultured together with a posterior hypothalamic slice, which contains histaminergic neurons [HI plus HY (POST)], and in the third culture system, a hippocampal slice was cultured together with an anterior hypothalamic slice devoid of histaminergic neurons [HI plus HY (ANT)].

Hippocampal and hypothalamic slice cultures were prepared from postnatal day 4 (P4) Sprague-Dawley rats using the modified method of Stoppini et al. (1991) as described in detail recently (Holopainen et al., 2001). Briefly, hippocampi and hypothalami taken from different rats were dissected, and placed immediately in cold Gey's balanced salt solution (Invitrogen, Paisley, UK) supplemented with glucose $(6.5 \mathrm{mg} / \mathrm{ml})$. Hippocampal slices $(300 \mu \mathrm{m})$ were cut perpendicular to the septotemporal axis, and hypothalamic slices $(300 \mu \mathrm{m})$ were cut vertically using a McIlwain tissue chopper. Based on our immunohistochemical studies (data not shown), the first four to five slices of the posterior end of the hypothalamus contained histaminergic neurons, and the subsequent four slices, which were devoid of histaminergic neurons, were considered as the anterior hypothalamic slices. Slices were placed on top of semipermeable membrane inserts (Millipore, Bedford, MA) in a six-well plate containing $1.2 \mathrm{ml}$ of culture medium (50\% of minimum essential medium, 25\% HBSS, 25\% heat-inactivated horse serum, 25 mм HEPES, supplemented with GlutaMaxII, and $6.5 \mathrm{mg} / \mathrm{ml}$ glucose, $\mathrm{pH}$ adjusted to 7.2). All reagents for slice cultures were purchased from Invitrogen. In cocultures, the fimbrial side of the hippocampal slice was placed in contact with the lateral side of the hypothalamic slice (see Fig. 1). Slices were cultured in an incubator $\left(37^{\circ} \mathrm{C}, 5 \% \mathrm{CO}_{2}\right)$ for $7 \mathrm{~d}$ with medium change twice per week. No antibiotics were used.

All treatments of animals were conducted in accordance with the guidelines set by the European Community Council Directives 86/609/ EEC, and had the approval of the Animal Use and Care Committee of the University of Turku. All efforts were made to minimize the pain, discomfort, and the number of experimental animals.

Pharmacological treatments of cultures. After $7 \mathrm{~d}$ in vitro, cultures were treated with KA ( $5 \mu \mathrm{m}$; Sigma, St. Louis, MO) alone or together with the other pharmacological compounds (see below) for $12 \mathrm{~h}$. In all pharmacological treatments, slices from at least three different culture sets were used. To study putative changes in histaminergic fiber density after KA treatment in HI plus HY (POST) a subset of inserts was transferred to new multiwell dishes containing normal, fresh culture medium, and further cultured for $48 \mathrm{~h}$ before staining.

To find out an optimal concentration and time for the inhibition of histamine synthesis by $\alpha$-fluoromethylhistidine ( $\alpha$-FMH), HI plus HY (POST) was incubated with different concentrations of $\alpha$-FMH (10 nM, $100 \mathrm{nM}$, and $1 \mu \mathrm{M}$; a kind gift from Dr. J. Kollonitsch, Merck Sharp and Dohme Research Laboratories, Rahway, NJ) for 6, 12, and $24 \mathrm{~h}$. In addition, to find out whether histamine, which disappeared from histaminergic fibers after $\alpha$-FMH treatment, would reappear in fibers during the next $12 \mathrm{~h}$ (the length of KA treatment), a subset of cultures was further incubated in normal medium for $12 \mathrm{~h}$. Immunostaining with the antihistamine antibody (see below) was used to verify the location of histamine in cell bodies and fibers. Fluoro-Jade B (FJB) staining (see below) was performed to study whether or not KA-induced neuronal degeneration was changed in the absence of endogenous histamine in histaminergic fibers innervating the hippocampus.

To study the effect of extracellularly applied histamine on neuronal survival in HI, different concentrations of histamine ( $1 \mathrm{nM}, 10 \mathrm{nM}, 100$ $\mathrm{nM}, 1 \mu \mathrm{M}, 10 \mu \mathrm{M}$, and $100 \mu \mathrm{M}$; Sigma) ( $n=13-20$ in each concentration) were added to hippocampal slices after $7 \mathrm{~d}$. After the $30 \mathrm{~min}$ incubation with histamine, KA $(5 \mu \mathrm{M})$ was added and slices were further incubated with both histamine and KA for $12 \mathrm{~h}$.

The effect of the histamine $\mathrm{H}_{1}$ and $\mathrm{H}_{3}$ receptors on KA-induced neuronal damage was studied in HI plus HY (POST), which was incubated together with different concentrations of the $\mathrm{H}_{1}$ receptor antagonists triprolidine ( $2 \mathrm{nM}, 20 \mathrm{nM}, 200 \mathrm{nM}$, and $2 \mu \mathrm{M} ; n=16-27$ in each concentration), and mepyramine ( $1 \mathrm{nM}, 10 \mathrm{nM}, 100 \mathrm{nM}$, and $1 \mu \mathrm{M} ; n=13-16$ in each concentration). The significance of the $\mathrm{H}_{3}$ receptor was studied by treating $\mathrm{HI}$ plus $\mathrm{HY}$ (POST) with the $\mathrm{H}_{3}$ receptor antagonists clobenpropit ( $10 \mathrm{nM}, 100 \mathrm{nM}, 1 \mu \mathrm{M}$, and $5 \mu \mathrm{M} ; n=12-16$ in each concentration) and thioperamide ( $1 \mathrm{nM}, 10 \mathrm{nM}, 100 \mathrm{nM}$, and $1 \mu \mathrm{M} ; n=12-16$ in each concentration). Thioperamide and clobenpropit were kind gifts from Drs. H. Timmerman and R. Leurs (Vrije University, Amsterdam, The Netherlands); all other compounds were from Sigma. KA ( $5 \mu \mathrm{M})$ was added 30 min after the antagonists and cultures were further incubated for $12 \mathrm{~h}$. Neuronal degeneration was detected with FJB staining (see below).

Immunostaining. During the entire staining procedure, cultured slices were attached to semipermeable membrane inserts and gentle rotation was used in all steps to evenly distribute the reagents. Before immunostaining, slices were briefly washed with cold PBS $(0.1 \mathrm{M}, \mathrm{pH} 7.2)$ followed by fixation overnight at $+4^{\circ} \mathrm{C}$ with a mixture containing $4 \%$ 1-ethyl-3(3dimethyl-aminopropyl)-carbodiimide (EDAC; Sigma) and 0.5\% paraformaldehyde (PFA; Sigma) in PBS. After fixation, slices were briefly washed with PBS containing $0.25 \%$ Triton X-100 (PBS-T). To decrease background staining, slices were preincubated with PBS-T containing $1 \%$ dimethylsulfoxide (DMSO) and $2 \%$ goat serum for $4-6 \mathrm{~h}$, and briefly washed with PBS-T. The antihistamine antibody (19C) (Panula et al., $1990)$ was diluted $(1: 10,000)$ in PBS-T containing $1 \%$ goat serum and slices were further incubated overnight at $+4^{\circ} \mathrm{C}$. After that, slices were washed with PBS-T and incubated overnight at $+4^{\circ} \mathrm{C}$ with the secondary antibody Alexa 488 (Invitrogen) diluted (1:1000) in PBS. After washing with PBS, semipermeable membranes with slices were cut from inserts, transferred to gelatin-coated glass slides, coverslipped, and examined with a confocal microscope (see below).

Fluoro-Jade B staining. FJB was used to study KA-induced neuronal degeneration as described in detail recently by Holopainen et al. (2004). This dye is an anionic tribasic fluorescent derivative with excitation peaks at 362 and $390 \mathrm{~nm}$, and an emission peak at $550 \mathrm{~nm}$, and it stains degenerating neurons and their processes regardless of the mechanism by which a nerve cell dies (Schmued and Hopkins, 2000). During the staining procedure, slices remained attached to the membrane, and gentle rotation was used in all steps to evenly distribute the reagents. Slices were fixed with $4 \%$ PFA for $1 \mathrm{~h}$ at room temperature, and then washed with PBS and water. Thereafter, slices were transferred to $0.06 \%$ potassium permanganate $\left(\mathrm{KMnO}_{4}\right)$ for 2-3 min, washed with water, and transferred to $0.001 \%$ FJB solution for $30 \mathrm{~min}$. Finally, slices were washed with water, detached from membranes, transferred to gelatin-coated glass slides, dried, immersed in xylene, coverslipped, and analyzed. Slices were used for FJB staining as follows: HI not treated with KA (control, $n=12$ ), HI treated with KA $(5 \mu \mathrm{M})$ for $12 \mathrm{~h}(n=33)$, HI plus HY (POST) treated with KA for $12 \mathrm{~h}(n=19)$, HI plus HY (ANT) treated with KA for $12 \mathrm{~h}$ $(n=19)$. 
Thionin staining. Slices were removed from semipermeable membranes to gelatin-coated glass slides and dried. For thionin staining, slices ( $n=8-12$ in each treatment) were rehydrated, stained in $0.1 \%$ thionin for $15-20 \mathrm{~s}$, washed in water to remove excess color, dehydrated in alcohol series, cleared in xylene, and coverslipped. An Olympus (Tokyo, Japan) U-TV1 X digital camera was used to capture pictures using an Olympus BX60 microscope, and pictures were further processed using Adobe (San Jose, CA) Photoshop (version 6.0) and Corel (Ottawa, Ontario, Canada) Draw (version 9.0).

Confocal microscopy and verification of neuronal damage. All specimens were examined with a Leica (Heidelberg, Germany) TCS SP confo-
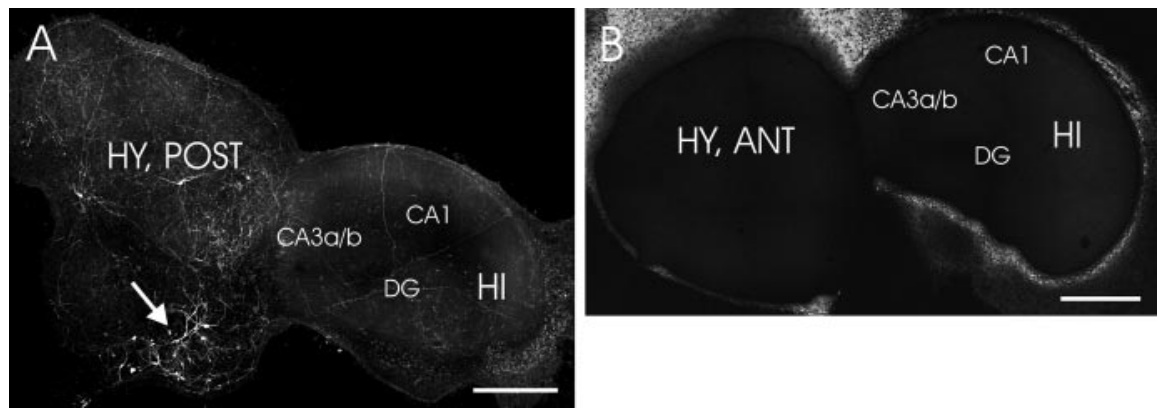

Figure 1. Representative images of histamine immunostaining in a coculture of the hippocampus and hypothalamus. $\boldsymbol{A}_{\text {, }}$ Histaminergic neurons (arrows), which are located in the posterior hypothalamic slice, distribute their neurites all over in $\mathrm{HI}$ plus HY (POST) (7 d in vitro). B, No histamine immunopositive staining was detected in HI plus HY (ANT). Different subregions of the hippocampus $C A 3 a / b, C A 1$, and dentate gyrus are indicated. Scale bars, $500 \mu \mathrm{m}$. DG, Dentate gyrus. cal microscopy system equipped with an argon-

krypton laser (Omnichrome; Melles Griot, Carlsbad, CA). The laser wavelength used for excitation of FJB and Alexa 488 was $488 \mathrm{~nm}$, and the emission detection window was $500-600 \mathrm{~nm}$. Occasionally, the emission detection settings were slightly changed for optimal performance. The images were acquired at $1-2 \mu \mathrm{m}$ steps, and analyzed with Leica TCS NT/SP Scanware (version 1.6.587) software. The most used algorithm was maximum projection, which determines the maximum of all intensity values in a stack of sections, and displays them in one single image. Reconstruction of the images of the whole hippocampal slice and the coculture were accomplished afterward from $1 \mathrm{~mm}^{2}$ maximum projections using Adobe Photoshop. Because our preliminary experiments indicated that KA treatment mainly damaged pyramidal neurons of the $\mathrm{CA} 3 \mathrm{a} / \mathrm{b}$ region, we focused our additional studies on this specific region. For our scoring analyses, the area of stained neurons (i.e., degenerating neurons) was measured from maximum projections using ImageJ software, which is freely available at http://rsb.info.nih.gov/ij. The following scoring system was used to evaluate the extent of the damage: $0=$ no FJB-stained neurons (regarded as normal), $1=1-100 \times 103 \mu \mathrm{m}^{2}, 2=$ $101-200 \times 103 \mu \mathrm{m}^{2}, 3=201-300 \times 103 \mu \mathrm{m}^{2}$, and $4=>300 \times 103 \mu \mathrm{m}^{2}$.

To further verify the results concerning the extent of neuronal damage, we counted the FJB-stained neurons throughout the entire thickness of the slice within the $250 \mu \mathrm{m}^{2}$ area of the central part of the CA3a/b pyramidal cell layer. For the counting, 10 slices were blindly selected from three different groups: (1) control HI cultured in normal medium, (2) HI with KA for $12 \mathrm{~h}$, and (3) HI plus HY (POST) treated with KA for $12 \mathrm{~h}$. In each slice, pyramidal neurons were counted in confocal optical sections of the $250 \mu \mathrm{m}^{2}$ region with Adobe Photoshop using the following procedure. The FJB-stained neurons were counted from the first optical section and marked with dots of one color (see Fig. $4 B$ ). The second optical section was opened, and the stained neurons were marked with a different color. After that, the second optical section was converted partly transparent in Adobe Photoshop and those neurons that were already counted in the first section were subtracted from the number of neurons in the second section. All optical images through the $z$-axis were analyzed using the same procedure. Finally, the number of FJB-stained degenerating neurons was summed up within the entire three-dimensional area. Final modification of pictures was accomplished in Corel Draw.

HPLC. To exclude the possibility that external histamine in the culture medium could have an effect on the survival of neurons, histamine content was determined in both horse serum and culture medium using HPLC equipped with a fluorometric detector. Briefly, samples were diluted in $10 \mathrm{vol}$ of $2 \%$ perchloric acid and centrifuged at $15,000 \times g$ for $15 \mathrm{~min}$. Histamine content was analyzed from the supernatants us- ing HPLC with postcolumn derivatization and fluorometric detection according to the method of Yamatodani et al. (1985). The detection limit was $10 \mathrm{pmol} / \mathrm{g}$ of the original sample.

Electrophysiological recording of spontaneous activity. To study KAinduced changes in spontaneous neuronal activity, which could modify to the neuroprotective effect of histaminergic neurons, $\mathrm{HI}$ and $\mathrm{HI}$ plus HY (POST) were cultured for $7 \mathrm{~d}$ and then incubated with $5 \mu \mathrm{M}$ KA for $6 \mathrm{~h}$. Our preliminary experiments indicated that the $6 \mathrm{~h}$ treatment time was optimal to detect functional changes without any obvious damage in hippocampal CA3 neurons. Control HI had no KA treatment. After the incubation, an insert with a slice was briefly washed and thereafter transferred to a dish containing an artificial CSF (aCSF) with the following composition (in mM): $124.0 \mathrm{NaCl}, 26.0 \mathrm{NaHCO}_{3}, 10.0$ D-glucose, 4.5 $\mathrm{KCl}, 1.2 \mathrm{NaH}_{2} \mathrm{PO}_{4}, 1.5 \mathrm{MgCl}_{2}$, and $2.0 \mathrm{CaCl}_{2}$. After equilibration $\left(35^{\circ} \mathrm{C}\right.$, maximum $1 \mathrm{~h}$ ), the slice was transferred to the recording chamber (capacity, $6 \mathrm{ml}$ ) mounted to a Leica DM IRB microscope. Slices were superfused with oxygenated $\left(95 \% \mathrm{O}_{2}\right.$ and $\left.5 \% \mathrm{CO}_{2}\right)$ aCSF during the entire experiment at a flow rate of $2 \mathrm{ml} / \mathrm{min}\left(30-32^{\circ} \mathrm{C}\right)$. Before electrophysiological recordings, slices were examined with the microscope, and slices showing any signs of degeneration or damage (i.e., decrease in transparency or damage caused by handling) were excluded from the study.

Extracellular field recordings were performed in the CA1 pyramidal layer with glass capillary microelectrodes $(<5 \mathrm{M} \Omega)$, which were pulled with a micropipette puller (Flaming Brown P87; Sutter Instruments, Novato, CA) and filled with $150 \mathrm{~mm} \mathrm{NaCl}$. After placement of the electrode in the CA1 pyramidal cell layer, the slice was left to stabilize for at least $10 \mathrm{~min}$. Thereafter, spontaneous extracellular activity was recorded for $20 \mathrm{~min}$. Signals were recorded using an Axoclamp-2B amplifier
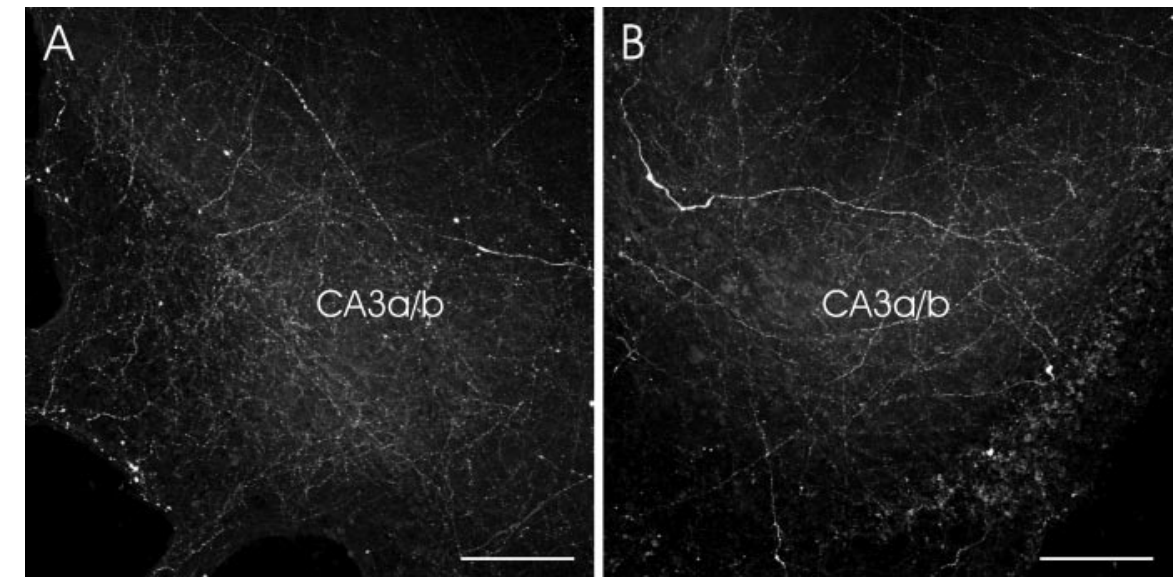

Figure 2. Representative images showing the histaminergic innervation in the $C A 3 \mathrm{a} / \mathrm{b}$ subregion of the hippocampus. $A, \operatorname{In} \mathrm{HI}$ plus HY (POST) (9 d in vitro), histaminergic fibers grew to the hippocampal slice. B, HI plus HY (POST) (7 d in vitro) was treated with $\mathrm{KA}(5 \mu \mathrm{M})$ for $12 \mathrm{~h}$ and, after the medium change, further cultured for $48 \mathrm{~h}$. Note that the density of fluorescent, histaminecontaining fibers in the CA3a/b region did not differ in these different experimental conditions. Scale bars, $100 \mu \mathrm{m}$. 

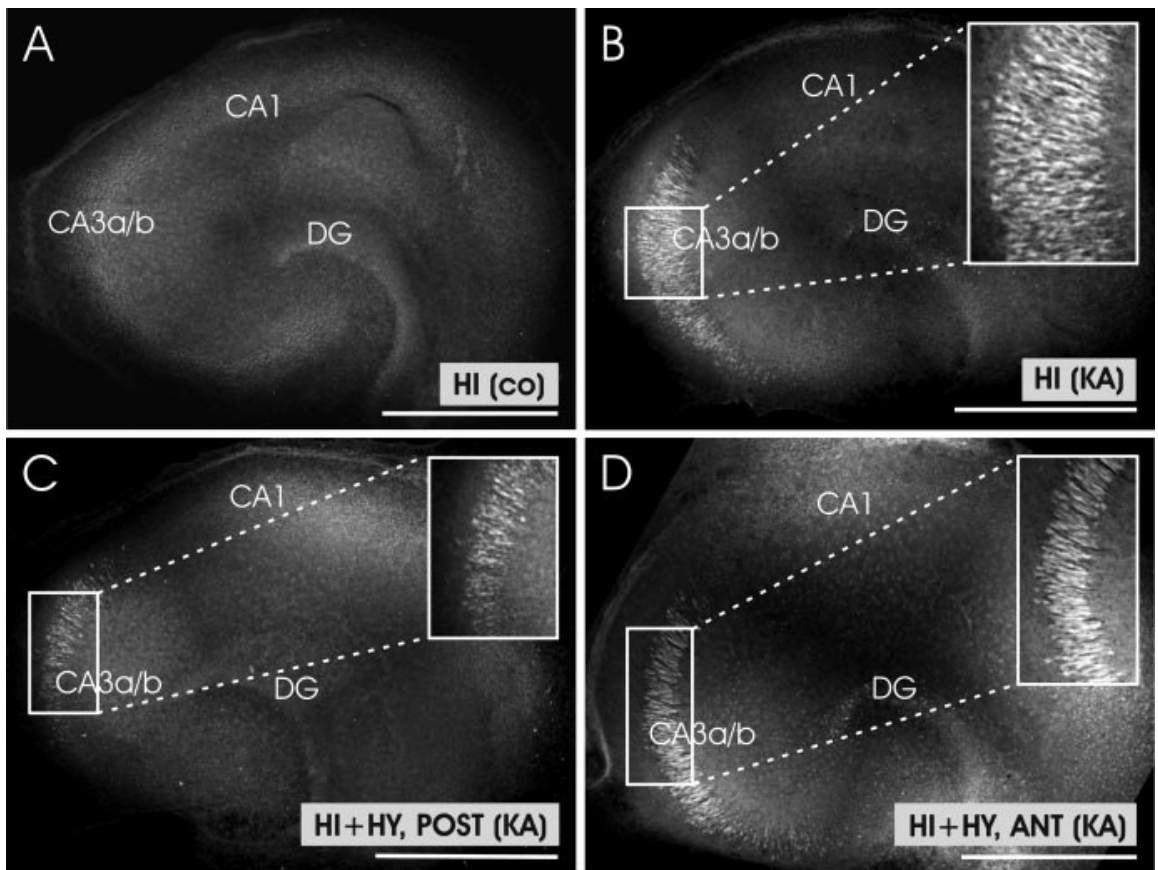

E

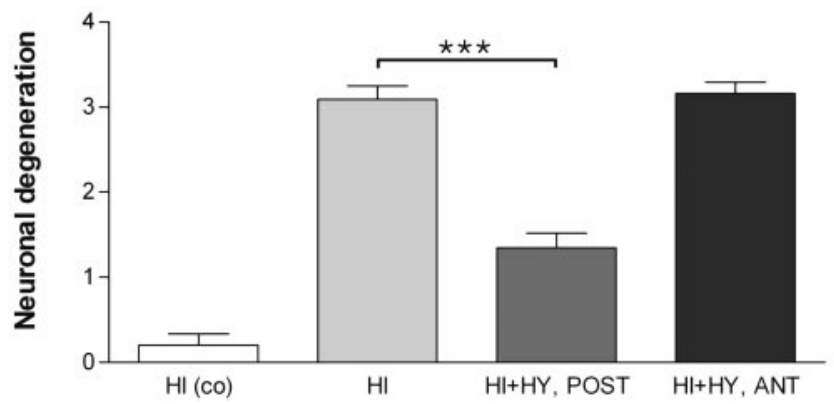

Figure 3. Representative confocal images of KA-induced neuronal degeneration in the hippocampal slices cultured for $7 \mathrm{~d}$ alone, or together with the posterior or anterior hypothalamic slice. $\boldsymbol{A}$, A representative image of control $\mathrm{HI}$ (no KA treatment) shows no FJB-stained neurons. $\boldsymbol{B}$, HI was treated with $\mathrm{KA}(5 \mu \mathrm{M})$ for $12 \mathrm{~h}$. Note the extensive staining of pyramidal neurons in the CA3a/b region. C, HI plus HY (POST) (7 d in vitro) was treated with KA ( $5 \mu \mathrm{m})$ for $12 \mathrm{~h}$. The area of FJB-stained, degenerating neurons in the $\mathrm{Ca} 3 \mathrm{a} / \mathrm{b}$ region is smaller when compared with Figure 3B.D, HI plus HY (ANT) (7 d in vitro) was treated with KA (5 $\mu \mathrm{m})$ for $12 \mathrm{~h}$. No clear decrease in neuronal damage is seen in the $C A 3 \mathrm{a} / \mathrm{b}$ region when compared with Figure $3 B$. $E$, According to our scoring system, KA-induced neuronal damage was significantly decreased in the CA3a/b region of HI plus HY (POST), whereas no significant decrease was detected in HI plus HY (ANT) compared with KA-treated HI. The results are given as means \pm SEM. $C_{0}$ Control (not KA treated); DG, dentate gyrus. ${ }^{* * *}$ Significant difference of $p<0.001$ (one-way ANOVA). Scale bars, $500 \mu \mathrm{m}$.

numbers after the FJB staining were assessed with one-way ANOVA with Tukey-Kramer multiple comparison test as a post hoc test. In the electrophysiological recordings, the statistical significance between $\mathrm{HI}$ and $\mathrm{HI}$ plus $\mathrm{HY}$ (POST) groups was determined using nonparametric Mann-Whitney test. Prism 4.0 program (GraphPad Software, San Diego, CA) was used in all statistical analyses, and the level of significance was set at $p<0.05$. Data are presented as means \pm SEM.

\section{Results}

Distribution of histaminergic fibers and neuroprotection in the coculture system This study was designed to examine the effect of histaminergic neurons on KAinduced neuronal damage in the immature hippocampus. For this purpose, we set up organotypic coculture systems, HI plus HY (POST) and HI plus HY (ANT). The HPLC results confirmed that no detectable levels of histamine were present in either horse serum or in culture medium, indicating that all histamine effecting the hippocampus was released from the histaminergic neurons located in the posterior hypothalamus. After $7 \mathrm{~d}$ in vitro, immunostainings with the antihistamine antibody in HI plus HY (POST) showed that histaminergic neurons survived well in the posterior hypothalamic slice, and histaminergic fibers grew into the hippocampal slice, densely innervating the whole hippocampal slice in a diffuse manner (Fig. $1 A$ ). In HI plus HY (ANT) no histamine staining was detected (Fig. $1 B$ ). Based on the visual estimation, the density of histaminergic innervation in $\mathrm{HI}$ plus $\mathrm{HY}$ (POST) did not change after the $12 \mathrm{~h} \mathrm{KA}$ treatment combined with the $48 \mathrm{~h}$ recovery period in the normal culture medium compared with HI plus HY (POST) without KA treatment (Fig. 2).

In the study of neuronal damage, no FJB-stained neurons were detected in control HI cultured $7 \mathrm{~d}$ in the normal me-

(Molecular Devices, Union City, CA), and data was stored and analyzed using the pClamp software. Digitization was performed using the $12 \mathrm{bit}$ A/D interface Digidata 1200 (Molecular Devices). Field recordings were analyzed offline with the Mini Analysis Program (Synaptosoft, Decatur, GA). The threshold for the automatic detection of fast field potential events was set at three times the baseline noise, and the detected events were also verified visually. For additional quantification of the activity, the data were arbitrarily divided into two categories (cf. Traub et al., 1996): (1) "interictal-type" positive discharges with an interevent interval longer than $3 \mathrm{~s}$, and (2) "ictal-type" synchronous bursts comprising of $>10$ discharges, having an interevent interval $<1 \mathrm{~s}$ and lasting $>3 \mathrm{~s}$.

In KA-treated HI, we were able to detect spontaneous ictal-type burst activity in 10 of 16 slices, and in HI plus HY (POST), in 10 of 12 slices. In contrast, in control HI slices (no KA-treatment) almost solely interictaltype spontaneous activity was detected. In only two of eight control HI slices, one single burst was detected in each slice. These recordings were excluded from the final statistical analysis, because they clearly represented exceptional activity for a control slice.

Statistical methods. The overall group differences in score and neuron dium, indicating a good viability of slices in the culture system (Fig. $3 A$ ), whereas $12 \mathrm{~h} \mathrm{KA}(5 \mu \mathrm{M})$ treatment resulted in neuronal damage in $\mathrm{HI}$ (Fig. $3 B$ ), the highest amount of degenerating neurons being in the $\mathrm{CA} 3 \mathrm{a} / \mathrm{b}$ subregion. The area of FJB-stained neurons was significantly reduced in HI plus HY (POST) when compared with the KA-treated HI (Fig. 3C,E). In HI plus HY (ANT) the amount of FJB-stained neurons did not differ from KA-treated HI (Fig. 3D,E).

Because the CA3a/b pyramidal neurons in immature hippocampal slices turned out to have high sensitivity to KA excitotoxicity (Ben-Ari and Cossart, 2000), the extent of damage was further studied focusing on this specific area. In accordance with the scoring results, the number of FJB-stained neurons in the 250 $\mu \mathrm{m}^{2}$ area of the CA3a/b region was significantly decreased in KA-treated HI plus HY (POST) $(17 \pm 4$, mean \pm SEM) when compared with KA-treated HI (74 \pm 7 , mean \pm SEM) (Fig. 4).

The conventional thionin staining was used to verify that the 

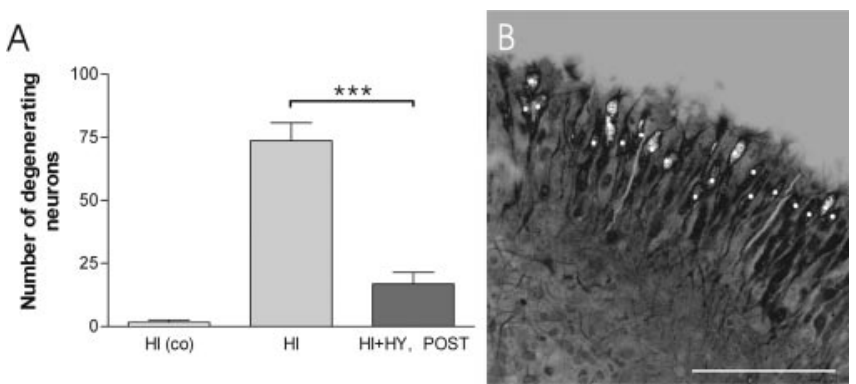

Figure 4. The number of FJB-stained, degenerating neurons in the $\mathrm{CA} 3 \mathrm{a} / \mathrm{b}$ region after the KA treatment. $A, \mathrm{HI}$ and $\mathrm{HI}$ plus HY (POST) (7 din vitro) were treated with KA $(5 \mu \mathrm{M})$ for $12 \mathrm{~h}$, and FJB-stained, degenerating neurons were counted in a $250 \mu \mathrm{m}^{2}$ area of the $C A 3 \mathrm{a} / \mathrm{b}$ region. $\mathrm{A}$ significant decrease was detected in the number of FJB-stained neurons in HI plus HY (POST) compared with $\mathrm{HI}$. Control $\mathrm{HI}$ were cultured in normal culture medium and not treated with $\mathrm{KA}$. ***Significant difference of $p<0.001$ (one-way ANOVA). co, Control (not KA treated). B, A representative confocal image of a single $250 \mu \mathrm{m}^{2}$ optical section of the CA3a/b region in $\mathrm{HI}$ (7 $\mathrm{d}$ in vitro), which was treated with $\mathrm{KA}$ for $12 \mathrm{~h}$. Counted cells at this level are marked with the white dots. The results are given as means \pm SEM. Scale bar, $100 \mu \mathrm{m}$.

Table 1. The electrophysiological characteristics of spontaneous activity in kainic acid-treated slices

\begin{tabular}{lllcl}
\hline Type of culture & $n$ & Frequency of bursts $(\mathrm{Hz})$ & $\begin{array}{c}\text { Interburst } \\
\text { interval }(s)\end{array}$ & $\begin{array}{l}\text { Amplitude of } \\
\text { discharges }(\mu \mathrm{V})\end{array}$ \\
\hline $\mathrm{HI}$ & 10 & $0.024 \pm 0.0027^{* * *}$ & $32 \pm 4^{* *}$ & $142 \pm 14$ \\
$\mathrm{HI}+\mathrm{HY}(\mathrm{POST})$ & 10 & $0.003 \pm 0.0003$ & $117 \pm 33$ & $140 \pm 13$ \\
\hline
\end{tabular}

The significant differences between the experimental groups are ${ }^{* * *} p<0.001$ and ${ }^{* *} p<0.01$.

decrease in neuronal degeneration as detected by FJB-staining in HI plus HY (POST) was not attributable to the disappearance of $\mathrm{CA} 3 \mathrm{a} / \mathrm{b}$ neurons after the $12 \mathrm{~h}$ KA treatment. In the control and KA-treated HI, as well in HI plus HY (POST), the CA3a/b region appeared normal with well preserved cell layer integrity (Fig. 5A$C)$. The results of thionin staining also verified that the FJB staining indicates those neurons that are damaged, and according to Schmued et al. (1997), in the process of dying, but not yet disappeared. However, after the $48 \mathrm{~h} \mathrm{KA} \mathrm{(5}$ $\mu \mathrm{M})$ treatment with the $48 \mathrm{~h}$ recovery period, thionin staining showed that in $\mathrm{HI}$ plus HY (POST) neurons were more protected in the $\mathrm{CA} 3 \mathrm{a} / \mathrm{b}$ region than in $\mathrm{HI}$ with the same treatment (Fig. 5D-F).

Spontaneous activity in control, KAtreated $\mathrm{HI}$ and $\mathrm{HI}$ plus HY (POST) slices To further elucidate the mechanisms behind the neuroprotective effect of histaminergic neurons, spontaneous electrical activity was recorded in HI slices cultured in normal medium, and in KA-treated $\mathrm{HI}$ and HI plus HY (POST). The main characteristics of the spontaneous activity in the KA-treated HI and HI plus HY (POST) slices are given in Table 1. In control slices, typically only infrequent spontaneous activity was seen (Fig. 6A). On the contrary, in $\mathrm{HI}$ slices treated with $5 \mu \mathrm{M} \mathrm{KA}$, the spontaneous activity was characterized by frequent ictal-type bursting (Fig. 6B). Interestingly, in HI plus HY (POST) slices, only occasional ictal-type bursts could be seen and the activity mainly consisted of interictal-type discharges (Fig. 6C). The occurrence of KA-induced spontaneous burst activity was significantly $(p<0.001)$ lower in HI plus HY (POST) when compared with HI (Table 1, Fig. 6D). Moreover, the interburst intervals were significantly $(p<0.01)$ longer in HI plus HY (POST) compared with HI, indicating the different bursting pattern in these two culture types (Table 1). The discharge amplitudes did not significantly differ between the $\mathrm{HI}$ and HI plus HY (POST) groups (Table 1).

\section{The effect of histamine content on neuronal damage}

$\alpha-\mathrm{FMH}$, which is a well known inhibitor of histamine synthesis, was used to further verify that histamine released from the histaminergic neurons was responsible for the improved survival of hippocampal CA3a/b neurons during KA treatment. No inhibition of histamine synthesis was detected after either 6 or $12 \mathrm{~h}$ at any tested $\alpha$-FMH concentrations (10 nM, $100 \mathrm{nM}$, and $1 \mu \mathrm{M})$ (Fig. 7A). However, $100 \mathrm{~nm}$ and $1 \mu \mathrm{M} \alpha$-FMH concentrations combined with a long treatment $(24 \mathrm{~h})$ lead to practically total disappearance of histamine-labeled fibers within the hypothalamus and hippocampus (Fig. $7 B, C$ ), but the cell bodies and proximal processes of histaminergic neurons remained positively labeled (Fig. 7C). The duration of the $\alpha$-FMH blocking effect in histamine synthesis was further studied in experiments in which cocultures were cultured in normal medium for $12 \mathrm{~h}$ (recovery phase) after the initial $\alpha$-FMH treatment (100 nM; $24 \mathrm{~h}$ ). The $12 \mathrm{~h}$ recovery phase did not lead to the reappearance of histaminepositive fibers in cultured posterior hypothalamic slices. This confirmed that histamine will not reappear in histaminergic fibers during the $12 \mathrm{~h} \mathrm{KA}$ treatment. The scoring analysis of FJBstained neurons showed that neuronal damage significantly increased in HI plus HY (POST) treated with $\alpha$-FMH (100 nM; $24 \mathrm{~h}$ ) and followed by KA ( $5 \mu \mathrm{M} ; 12 \mathrm{~h}$ ) when compared with HI plus HY (POST) without $\alpha$-FMH treatment (Fig. 7D). To study
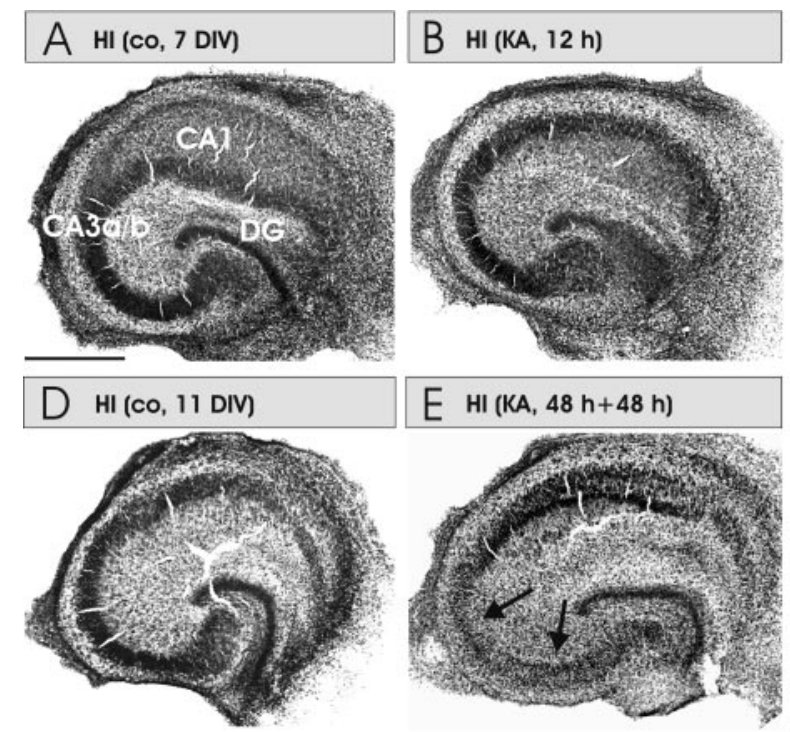

Figure 5. Representative images of thionin-stained cultures of HI, HI plus HY (POST), and HI plus HY (ANT). $\boldsymbol{A}$, The control (co) HI cultured for 7 d in normal medium. $\boldsymbol{B}$, HI was treated with KA (5 $\mu \mathrm{m})$ for $12 \mathrm{~h}$. No decrease in neuronal density was detected. $\boldsymbol{C}$, $\mathrm{HI}$ plus HY (POST) treated with KA for $12 \mathrm{~h}$. This figure corroborates that decrease in FJB-stained neurons in the coculture with histaminergic neurons (Figs. 3, 4) is not caused by the decrease in neuronal density in the CA3a/b area. D. The control HI cultured for $11 \mathrm{~d}$ in normal medium. $\boldsymbol{E}$, HI was treated with $\mathrm{KA}(5 \mu \mathrm{M})$ for $48 \mathrm{~h}$ and followed by a $48 \mathrm{~h}$ recovery period in the normal culture medium. Note that pyramidal neurons have disappeared in the CA3a/b region (arrows). $\boldsymbol{F}$, HI plus HY (POST) treated with KA (5 $\mu \mathrm{M})$ for $48 \mathrm{~h}$ followed by a $48 \mathrm{~h}$ recovery period in the normal medium. CA3a/b and CA3c pyramidal neurons are clearly better preserved in $\boldsymbol{F}$ than in $\boldsymbol{E}$ (arrows). Scale bar: (in $\boldsymbol{A}) \boldsymbol{A}-\boldsymbol{F}, 500 \mu \mathrm{m}$. 
A

HI (co)

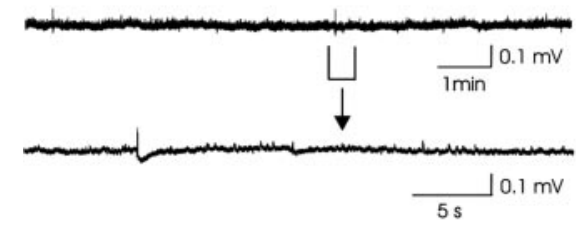

B
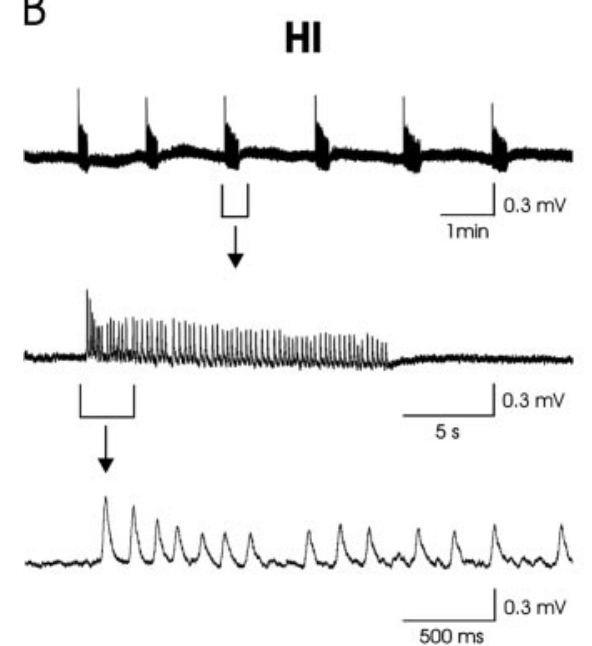

C
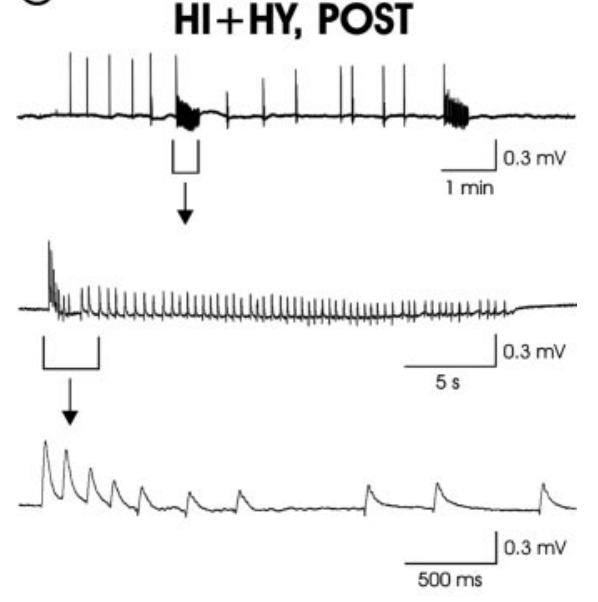

D

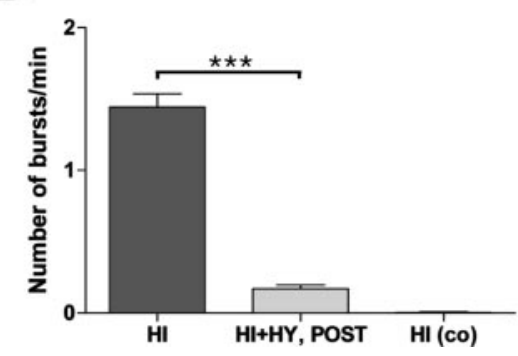

Figure 6. Spontaneous electrical activity recorded in the CA1 region of cultured hippocampal slices. A, A representative recording in a control hippocampal slice, $\mathrm{HI}$ (co). A sample trace showing a 10 min recording of spontaneous activity is shown (top). The bottom shows an expanded time scale trace taken from the same recording from the time interval indicated. $\boldsymbol{B}$, Spontaneous activity after the $6 \mathrm{~h} \mathrm{KA}$ treatment in HI shows intense ictal-type bursting. A 10 min sample recording is shown (top). Expanded time scales show the typical abrupt onset of the burst followed by repetitious positive discharges (middle, bottom). C, In HI plus HY (POST), only occasional bursts were detected, whereas inter-ictal type activity occurred frequently. The top shows a 10 min sample recording. The middle and bottom show an expanded time scale showing a typical isolated positive discharge. $\boldsymbol{D}$, The mean ( \pm SEM) number of KA-induced bursts/min during the 20 min recording period was significantly $\left({ }^{* * *} p<0.001\right.$ ) lower in HI plus HY (POST) compared with HI.

whether extracellularly applied histamine produces the neuroprotective effect detected in HI plus HY (POST), hippocampal slices were cultured alone and treated with KA $(5 \mu \mathrm{M} ; 12 \mathrm{~h})$ together with different concentrations of histamine (from $1 \mathrm{~nm}$ to $100 \mu \mathrm{M}$ ). At $1 \mathrm{~nm}$ histamine, the amount of FJB-stained neurons significantly decreased, whereas at $10 \mathrm{nM}$ to $100 \mu \mathrm{M}$ histamine concentrations, the neuroprotective effect of histamine dosedependently attenuated in the CA3a/b region (Fig. 8).

\section{The significance of $\mathrm{H}_{1}$ and $\mathrm{H}_{3}$ receptors in the neuroprotection}

The histamine receptor subtypes involved in the detected neuroprotective effect were studied using specific antagonists for $\mathrm{H}_{1}$ and $\mathrm{H}_{3}$ receptors in $\mathrm{HI}$ plus $\mathrm{HY}$ (POST). The $\mathrm{H}_{1}$ receptor antagonists triprolidine ( $2 \mathrm{~nm}$ to $2 \mu \mathrm{M}$ ) (Fig. $9 A$ ) and mepyramine (1 nм to $1 \mu \mathrm{M}$ ) (Fig. 9B) dose-dependently decreased the neuroprotection, this effect being significant at low micromolar concentrations of triprolidine $(2 \mu \mathrm{M})$ and mepyramine $(1 \mu \mathrm{M})$. The $\mathrm{H}_{3}$ receptor-specific antagonist thioperamide (1 $\mathrm{nm}$ to $1 \mu \mathrm{M})$ significantly increased the neuroprotective effect at $1 \mu \mathrm{M}$ concentration in HI plus HY (POST) (Fig. 10A), whereas clobenpropit (10 nM to $5 \mu \mathrm{M}$ ) had no significant effect at any concentration (Fig. $10 B)$.

\section{Discussion}

The main novel finding of this study is that histaminergic neurons decreased KAinduced neuronal damage in the pyramidal CA3a/b region of the immature hippocampus in vitro. The neuroprotective effect was not detected either in HI plus HY (ANT) or when histamine synthesis was inhibited by $\alpha$-FMH in HI plus HY (POST), suggesting a specific role for histamine rather than for other substances present in tuberomammillary neurons. Moreover, the $\mathrm{H}_{3}$ receptor antagonist thioperamide further increased, and the $\mathrm{H}_{1}$ receptor antagonists triprolidine and mepyramine decreased the neuroprotective effect of histaminergic neurons, suggesting that the neuroprotective effect may at least partly be mediated through $\mathrm{H}_{1}$ and $\mathrm{H}_{3}$ receptors.

\section{Neuronal degeneration in the hippocampus cultured together with the posterior hypothalamus}

The inhibitory effect of the histaminergic neuron system on seizures has been assigned in several studies (Scherkl et al., 1991; Yokoyama et al., 1992; Kamei, 2001; Yawata et al., 2004), but a possible neuroprotective effect of histaminergic neurons has attained less attention. In our study, the coculture system serves as an excellent model to study the effect of histaminergic neurons on neuronal damage in the hippocampus. We show that histaminergic neurons abundantly innervated the nearby situated hippocampus in the in vitro conditions, and as shown previously, they also seem to preserve their main morphological and physiological characteristics in culture conditions (Diewald et al., 1997). In our previous study, KA treatment has resulted in region-selective, irreversible necrotic damage in $\mathrm{CA} 3 \mathrm{a} / \mathrm{b}$ neurons in immature hippocampal slices prepared from P6-7 rats (Holopainen et al., 2001, 2004). According to our present novel findings, this KA-induced neuronal damage in the $\mathrm{CA} 3 \mathrm{a} / \mathrm{b}$ region was significantly ameliorated in the presence of histaminergic neurons. However, this neuroprotective effect was not related to an increase in density of histaminergic fibers.

FJ dyes have turned out to be useful tools in determining neuronal damage after different neurotoxic insults (Schmued et al., 1997; Schmued and Hopkins, 2000). This staining has been shown to be more sensitive than hematoxylin and eosin or Nissltype staining, with its sensitivity being comparable with suppressed silver techniques (Schmued et al., 1997). Although the exact staining mechanism is not known, this method is considered to be reliable in detecting neuronal damage. However, one should keep in mind that FJB can be only used at the early stages of neuronal degeneration when neurons are damaged, and in the process of dying. In our study, the conventional thionin staining did not show neuronal loss after the $12 \mathrm{~h}$ insult, indicating that the damaged pyramidal neurons were not yet disappeared. However, after the $48 \mathrm{~h} \mathrm{KA}$ treatment and the recovery period, disap- 

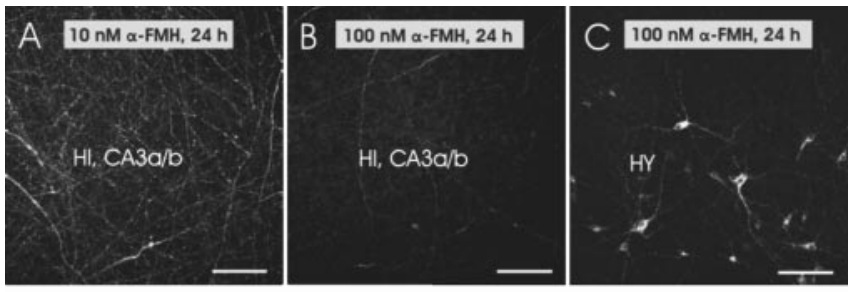

D

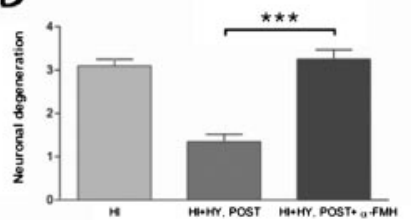

Figure 7. Histamine immunostaining and neuronal damage after the $\alpha$-FMH treatment. $\boldsymbol{A}_{\boldsymbol{t}}$ $\mathrm{HI}$ plus HY (POST) was treated with $10 \mathrm{~nm} \alpha$-FMH for $24 \mathrm{~h}$. Histaminergic innervation was very dense within the hippocampal CA3a/b subregion in HI plus HY (POST). B, Histaminergic innervation has almost totally disappeared in the CA3a/b region in HI plus HY (POST) after treatment with $100 \mathrm{~nm} \alpha$-FMH for $24 \mathrm{~h}$. C, In HI plus HY (POST), histamine-immunopositive cell bodies and proximal processes in the hypothalamus after $100 \mathrm{~nm} \alpha$-FMH-treatment for $24 \mathrm{~h}$. $\boldsymbol{D}$, The statistical analyses show that KA-induced $(5 \mu \mathrm{m} ; 12 \mathrm{~h})$ neuronal damage is significantly increased (*** $<0.001$; one-way ANOVA) in $\alpha$-FMH-treated (100 nm; $24 \mathrm{~h}$ ) HI plus HY (POST) compared with HI plus HY (POST) without $\alpha$-FMH treatment. The results are given as means \pm SEM. Scale bars: $A-C, 100 \mu \mathrm{m}$.

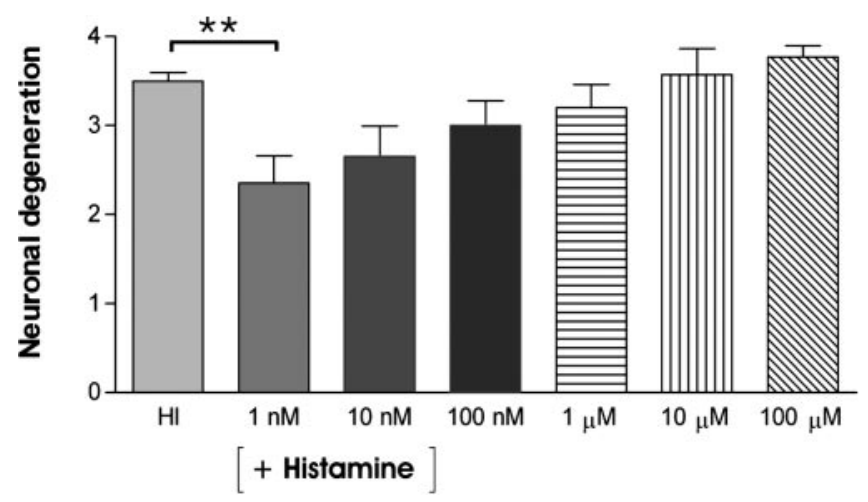

Figure 8. The effect of extracellularly applied histamine on neuronal degeneration in the hippocampal CA3a/b region. $\mathrm{HI}$ (7 d in vitro) was treated with $\mathrm{KA}(5 \mu \mathrm{M}, 12 \mathrm{~h})$ together with different histamine concentrations. Low histamine concentration (1 nM) significantly $\left({ }^{* *} p<\right.$ 0.01 ; one-way ANOVA) decreased neuronal degeneration in the CA3a/b region compared with $\mathrm{HI}$, which was treated with KA without any added histamine (HI). At higher histamine concentrations $(10 \mathrm{nM}-100 \mu \mathrm{M})$, the amount of FJB-stained neurons increased dose-dependently but did not significantly exceed the extend of damage seen in $\mathrm{HI}$ treated with KA. The results are given as means \pm SEM.

pearance of neurons in CA3a/b region was clearly detected in $\mathrm{HI}$, whereas in $\mathrm{HI}$ plus $\mathrm{HY}$ (POST) the $\mathrm{CA} 3 \mathrm{a} / \mathrm{b}$ region was better preserved.

In addition to histamine released from histaminergic neurons, additional neuroprotective factors present in horse serum or hypothalamic slice might have contributed to enhanced neuronal survival during KA treatment. In fact, excitotoxic neuronal damage has been ameliorated by different neurotrophic factors (Mattson et al., 1993; Culmsee et al., 1999; Cheng et al., 2004). In our culture system, however, the possible protective effect of serum-derived factors would have had similar effect on HI, HI plus HY (POST), and HI plus HY (ANT). The possibility that some other neuroprotective compounds were released from the posterior hypothalamic slice remains unclarified. However, the fact that $\alpha$-FMH treatment resulted in disappearance of hista-
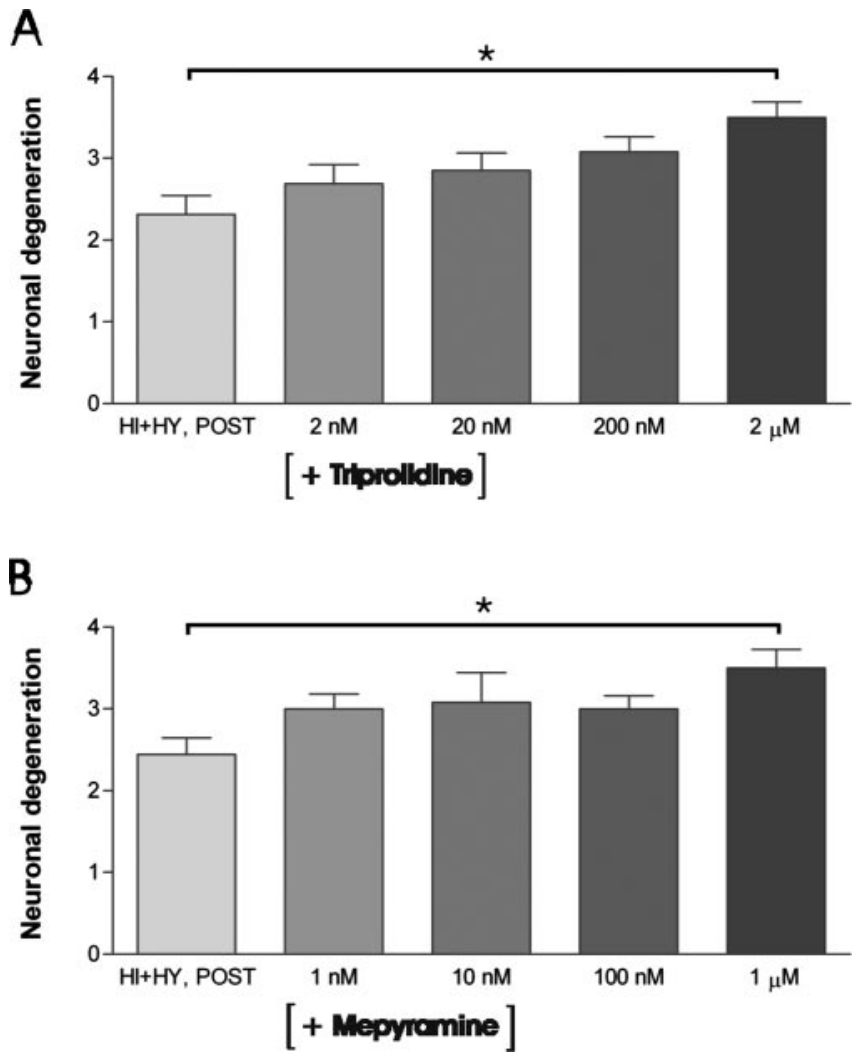

Figure 9. The effect of $\mathrm{H}_{1}$ receptor antagonists triprolidine and mepyramine on $\mathrm{KA}$-induced neuronal damage in the CA3a/b region. $A$, HI plus HY (POST) was treated with KA $(5 \mu \mathrm{M})$ together with different concentrations ( $2 \mathrm{~nm}$ to $2 \mu \mathrm{M}$ ) of $\mathrm{H}_{1}$ receptor antagonist triprolidine for 12h. Triprolidine treatment increased KA-induced neuronal degeneration dose-dependently in the CA3a/b area in HI plus HY (POST) compared with HI plus HY (POST) without triprolidine treatment. The significant increase in neuronal damage was detected at a $2 \mu \mathrm{m}$ concentration of triprolidine. $\boldsymbol{B}$, HI plus HY (POST) was treated with KA (5 $\mu \mathrm{m})$ together with different concentrations (1 nм to $1 \mu \mathrm{M}$ ) of $\mathrm{H}_{1}$ receptor antagonist mepyramine for $12 \mathrm{~h}$. Mepyramine increased dose-dependently KA-induced neuronal degeneration in the CA3a/b area in HI plus HY (POST) compared with HI plus HY (POST) without mepyramine. The significant increase in neuronal damage was detected at a $1 \mu \mathrm{m}$ concentration of mepyramine. The results are given as means \pm SEM. *Significant difference of $p<0.05$ (one-way ANOVA).

mine from histaminergic fibers, and enhanced KA-induced neuronal damage in the coculture together with the effects of the $\mathrm{H}_{1}$ and $\mathrm{H}_{3}$ receptors antagonists support the idea that the neuroprotective effect was mediated by histamine.

Tuberomammillary neurons themselves contain also other neuroprotective compounds (e.g., GABA and galanin) (Airaksinen et al., 1992; Kukko-Lukjanov and Panula, 2003). Thus, histamine released either alone or coreleased together with other neurotransmitters may have a different effect on degenerating neurons. Based on the fact that GABA is the well documented main inhibitory neurotransmitter in epilepsy (Sperk et al., 2004), and galanin is a neuropeptide, which has an inhibitory role in epileptic seizures (Mazarati et al., 2000; Kokaia et al., 2001), the neuroprotective effect might be more pronounced in the case of histamine coreleased with GABA and/or galanin than when histamine is released alone. The physiological significance of the GABA and galanin colocalization in the histaminergic neurons is not known, but it might have an important role in extreme physiological conditions such as epileptic seizures.

\section{Mechanisms of histamine-mediated neuroprotective effect}

In KA-treated HI plus HY (POST), burst activity in the CA1 region was significantly lower when compared with HI. This sug- 

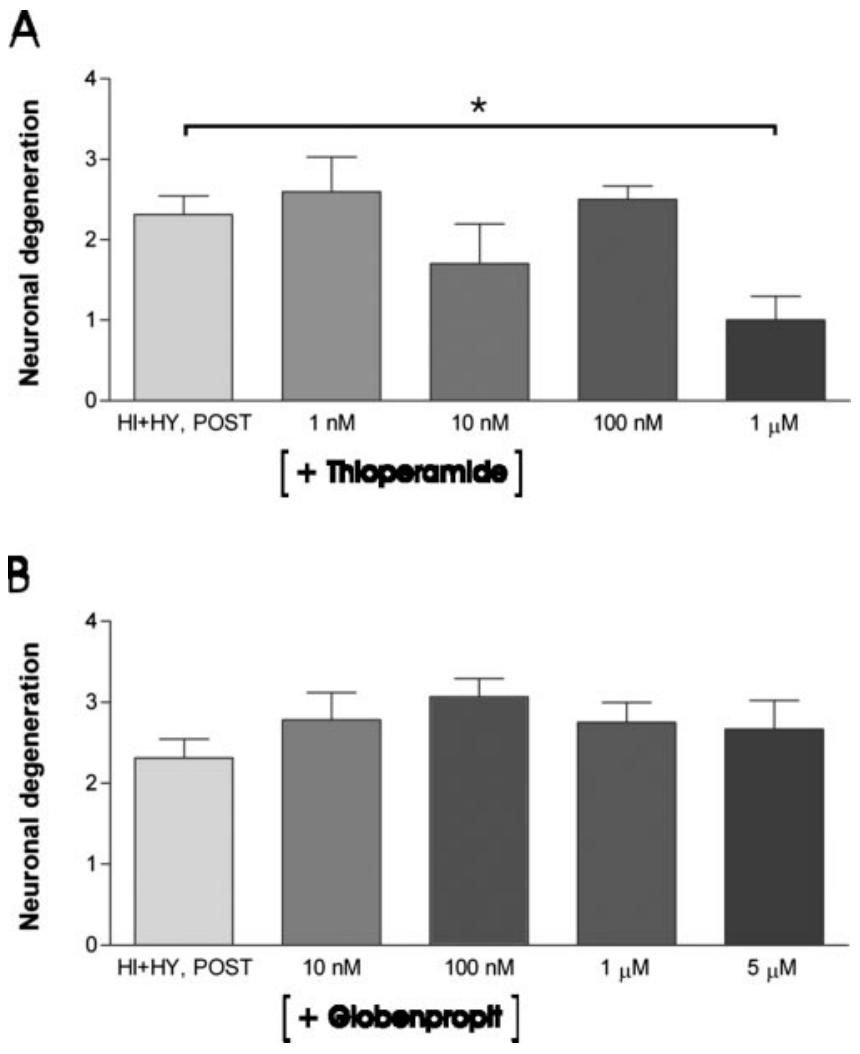

Figure 10. The effect of $\mathrm{H}_{3}$ receptor antagonists thioperamide and clobenpropit on $\mathrm{KA}$ induced neuronal damage in HI plus HY (POST). $A$, Thioperamide significantly $\left({ }^{*} p<0.05\right.$; one-way ANOVA) decreased the amount of FJB-stained neurons in the $\mathrm{CA3}$ a/b area in HI plus HY (POST) at a $1 \mu \mathrm{m}$ concentration compared with HI plus HY (POST) treated with KA ( $5 \mu \mathrm{m} ; 12 \mathrm{~h}$ ). $B$, The $\mathrm{H}_{3}$ receptor antagonist clobenpropit did not change the amount of FJB-stained neurons in the $C A 3 a / b$ area at any concentration. The results are given as means \pm SEM.

gests that histaminergic innervation attenuates KA-induced increased excitatory activity, and could thus ameliorate excitotoxic nerve cell damage at least partly through this mechanism. The idea is well in line with the results showing tight correlation between the increased spontaneous network activity and neuronal degeneration in the CA1 area in glutamate-treated organotypic hippocampal slices (Lahtinen et al., 2001). Moreover, increased NMDA receptor activity leading to excess of calcium ions in intracellular compartments is suggested to be the main contributor for the activation of cascades leading to neuronal death (Arundine and Tymianski, 2003). However, current epileptic drugs that are designed to decrease excitation or increase inhibition have shown only mild-to-moderate neuroprotective effect in epilepsy (Pitkanen, 2002). The histaminergic neuron system, which regulates the activity of many brain areas, could be a promising target for development of new antiepileptic drugs.

$\alpha$-FMH treatment has increased ischemic neuronal damage, this effect being mediated through $\mathrm{H}_{1}$ and $\mathrm{H}_{3}$ receptors (Adachi et al., 1993). The $\mathrm{H}_{3}$ receptor acts as an autoreceptor regulating histamine synthesis and release (Arrang et al., 1983; Takeshita et al., 1998; Torrent et al., 2005), and through its heteroreceptor it may inhibit release of other neurotransmitters (e.g., glutamate and GABA) (Brown and Haas, 1999; Korotkova et al., 2002). In our study, thioperamide increased the neuroprotective effect of histaminergic neurons, whereas clobenpropit did not have any effect. The reason for this difference might be in their binding mechanisms, interaction with different $\mathrm{H}_{3}$ receptor subtypes, or in receptor coupling (West et al., 1990; Clark and Hill, 1995). Indeed, systemic KA induces isoform-specific $\mathrm{H}_{3}$ receptor mRNA expression in the hippocampus of adult rats (Lintunen et al., 2005). Moreover, difference in the regulation of GABA release might be one explanation, because thioperamide seems to increase release of GABA whereas clobenpropit has no effect (Yamamoto et al., 1997). Finally, the lack of detectable neuroprotective effect of clobenpropit might be attributable to the fact that when it blocks the autoreceptor function, an increase in histamine release ameliorates neuronal damage, whereas the blockade of its heteroreceptor function increases glutamate release, which enhances neuronal damage.

In the immature brain, the classical antihistamines cause seizures even when administered in clinically relevant doses (Yokoyama et al., 1993; Yokoyama, 2001). The $\mathrm{H}_{1}$ receptor antagonists, which now dose-dependently abolished the neuroprotective effect of histaminergic neurons, could enhance NMDA receptor-mediated neuronal death by increasing calcium influx and oxygen radical formation in cultured cerebellar neurons (Diaz-Trelles et al., 2000). On the other hand, the $\mathrm{H}_{1}$ receptor antagonist mepyramine has abolished the histamine-induced increase in firing frequency in GABAergic neurons of the substantia nigra (Korotkova et al., 2002). In accordance, the $\mathrm{H}_{1}$ receptor mediates the decrease in 5-hydroksytryptamine release indirectly through GABAergic neurons (Son et al., 2001). Both the NMDA and $\mathrm{GABA}_{\mathrm{A}}$ receptor-mediated mechanisms could be involved in the neurotoxic effects of $\mathrm{H}_{1}$ receptor antagonists, although additional studies are needed to clarify the mechanisms involved.

Histamine, when added to the culture medium, significantly attenuated the KA-induced neuronal damage in the CA3a/b region at a low (1 nM) concentration. Interestingly, its neuroprotective effect dose-dependently decreased at higher concentrations. The reason for this strict concentration-dependent effect could be attributable to the fact that, when present at high concentrations, histamine also binds to NMDA receptors, enhancing receptor-mediated excitatory synaptic currents (Bekkers, 1993; Brown et al., 1995), which may contribute to excitotoxic neuronal damage. In accordance with this idea, NMDA receptormediated excitotoxic damage has been augmented in hippocampal neurons cultured together with either histamine $(30 \mu \mathrm{M})$, or with mast cells, which contain high histamine levels (Skaper et al., $2001)$. Moreover, the application of histamine $(100 \mu \mathrm{M})$ to brain slices containing striatal neurons has resulted in a concentrationdependent, NMDA receptor-mediated neuronal swelling, ultimately leading to $\mathrm{H}_{2}$ receptor-mediated neuronal death (Colwell and Levine, 1997). Although the exact intracellular mechanisms mediating the neurotoxic effect of high histamine concentrations are poorly known, the effects mediated through NMDA receptors could be of importance, because the normal NMDA receptor function is of crucial importance for neuronal survival in the immature hippocampus (Gould et al., 1994; Katz and Shatz, 1996; Ben-Ari, 2001; Manent et al., 2005), and any disturbances may enhance neuronal damage.

The results of our present study indicate that histamine released from histaminergic neurons ameliorates the KA-induced CA3 pyramidal cell damage. The effect seems to be mediated through $\mathrm{H}_{1}$ and $\mathrm{H}_{3}$ receptors, although the contribution of other neurotransmitters coreleased with histamine from histaminergic fibers cannot be exclusively ruled out. Our present results suggest that the coculture method used serves as an excellent tool to study the factors regulating neuronal survival of the immature hip- 
pocampus in response to neurotoxic compounds in a well controlled environment.

\section{References}

Adachi N, Oishi R, Itano Y, Yamada T, Hirakawa M, Saeki K (1993) Aggravation of ischemic neuronal damage in the rat hippocampus by impairment of histaminergic neurotransmission. Brain Res 602:165-168.

Airaksinen MS, Alanen S, Szabat E, Visser TJ, Panula P (1992) Multiple neurotransmitters in the tuberomammillary nucleus: comparison of rat, mouse, and guinea pig. J Comp Neurol 323:103-116.

Arrang JM, Garbarg M, Schwartz JC (1983) Auto-inhibition of brain histamine release mediated by a novel class $\left(\mathrm{H}_{3}\right)$ of histamine receptor. Nature 302:832-837.

Arundine M, Tymianski M (2003) Molecular mechanisms of calciumdependent neurodegeneration in excitotoxicity. Cell Calcium 34:325-337.

Bekkers JM (1993) Enhancement by histamine of NMDA-mediated synaptic transmission in the hippocampus. Science 261:104-106.

Ben-Ari Y (2001) Developing networks play a similar melody. Trends Neurosci 24:353-360.

Ben-Ari Y, Cossart R (2000) Kainate, a double agent that generates seizures: two decades of progress. Trends Neurosci 23:580-587.

Brown RE, Haas HL (1999) On the mechanism of histaminergic inhibition of glutamate release in the rat dentate gyrus. J Physiol (Lond) 515:777-786.

Brown RE, Fedorov NB, Haas HL, Reymann KG (1995) Histaminergic modulation of synaptic plasticity in area CAl of rat hippocampal slices. Neuropharmacology 34:181-190.

Bruce AJ, Sakhi S, Schreiber SS, Baudry M (1995) Development of kainic acid and $\mathrm{N}$-methyl-D-aspartic acid toxicity in organotypic hippocampal cultures. Exp Neurol 132:209-219.

Buckmaster PS, Dudek FE (1997) Neuron loss, granule cell axon reorganization, and functional changes in the dentate gyrus of epileptic kainatetreated rats. J Comp Neurol 385:385-404.

Cheng H, Fu YS, Guo JW (2004) Ability of GDNF to diminish free radical production leads to protection against kainate-induced excitotoxicity in hippocampus. Hippocampus 14:77-86.

Clark E, Hill S (1995) Differential effect of sodium ions and guanine nucleotides on the binding of thioperamide and clobenpropit to histamine H3-receptors in rat cerebral cortical membranes. Br J Pharmacol 114:357-362.

Colwell CS, Levine MS (1997) Histamine modulates NMDA-dependent swelling in the neostriatum. Brain Res 766:205-212.

Culmsee C, Semkova I, Krieglstein J (1999) NGF mediates the neuroprotective effect of the beta2-adrenoceptor agonist clenbuterol in vitro and in vivo: evidence from an NGF-antisense study. Neurochem Int 35:47-57.

Diaz-Trelles R, Novelli A, Vega JA, Marini A, Fernandez-Sanchez MT (2000) Antihistamine terfenadine potentiates NMDA receptor-mediated calcium influx, oxygen radical formation, and neuronal death. Brain Res 880:17-27.

Diewald L, Heimrich B, Busselberg D, Watanabe T, Haas HL (1997) Histaminergic system in co-cultures of hippocampus and posterior hypothalamus: a morphological and electrophysiological study in the rat. Eur J Neurosci 9:2406-2413.

Fisher RS, Alger BE (1984) Electrophysiological mechanisms of kainic acidinduced epileptiform activity in the rat hippocampal slice. J Neurosci 4:1312-1323.

Frotscher M, Zafirov S, Heimrich B (1995) Development of identified neuronal types and of specific synaptic connections in slice cultures of rat hippocampus. Prog Neurobiol 45:143-164.

Fujii Y, Tanaka T, Harada C, Hirai T, Kamei C (2003) Epileptogenic activity induced by histamine $\mathrm{H}(1)$ antagonists in amygdala-kindled rats. Brain Res 991:258-261.

Gerald M, Richter N (1976) Studies on the effects of histaminergic agents on seizure susceptibility in mice. Psychopharmacology 46:277-282.

Gould E, Cameron HA, McEwen BS (1994) Blockade of NMDA receptors increases cell death and birth in the developing rat dentate gyrus. J Comp Neurol 340:551-565.

Haas H, Panula P (2003) The role of histamine and the tuberomamillary nucleus in the nervous system. Nat Rev Neurosci 4:121-130.

Holopainen IE, Lauren HB (2003) Neuronal activity regulates GABA $A_{A}$ re- ceptor subunit expression in organotypic hippocampal slice cultures. Neuroscience 118:967-974.

Holopainen IE, Lauren HB, Romppanen A, Lopez-Picon FR (2001) Changes in neurofilament protein-immunoreactivity after kainic acid treatment of organotypic hippocampal slice cultures. J Neurosci Res 66:620-629.

Holopainen IE, Jarvela J, Lopez-Picon FR, Pelliniemi LJ, Kukko-Lukjanov TK (2004) Mechanisms of kainate-induced region-specific neuronal death in immature organotypic hippocampal slice cultures. Neurochem Int 45:1-10.

Kamei C (2001) Involvement of central histamine in amygdaloid kindled seizures in rats. Behav Brain Res 124:243-250.

Kamei C, Ohuchi M, Sugimoto Y, Okuma C (2000) Mechanism responsible for epileptogenic activity by first-generation $\mathrm{H}_{1}$-antagonists in rats. Brain Res 887:183-186.

Katz LC, Shatz CJ (1996) Synaptic activity and the construction of cortical circuits. Science 274:1133-1138.

Kiviranta T, Tuomisto L, Airaksinen EM (1995) Histamine in cerebrospinal fluid of children with febrile convulsions. Epilepsia 36:276-280.

Kokaia M, Holmberg K, Nanobashvili A, Xu ZQ, Kokaia Z, Lendahl U, Hilke S, Theodorsson E, Kahl U, Bartfai T, Lindvall O, Hokfelt T (2001) Suppressed kindling epileptogenesis in mice with ectopic overexpression of galanin. Proc Natl Acad Sci USA 98:14006-14011.

Korotkova TM, Haas HL, Brown RE (2002) Histamine excites GABAergic cells in the rat substantia nigra and ventral tegmental area in vitro. Neurosci Lett 320:133-136.

Kukko-Lukjanov TK, Panula P (2003) Subcellular distribution of histamine, GABA and galanin in tuberomamillary neurons in vitro. J Chem Neuroanat 25:279-292.

Lahtinen H, Autere A-M, Paalasmaa P, Lauri SE, Kaila K (2001) Post-insult activity is a major cause of delayed neuronal death in organotypic hippocampal slices exposed to glutamate. Neuroscience 105:131-137.

Lintunen M, Sallmen T, Karlstedt K, Panula P (2005) Transient changes in the limbic histaminergic system after systemic kainic acid-induced seizures. Neurobiol Dis 20:155-169.

Liu W, Liu R, Chun JT, Bi R, Hoe W, Schreiber SS, Baudry M (2001) Kainate excitotoxicity in organotypic hippocampal slice cultures: evidence for multiple apoptotic pathways. Brain Res 916:239-248.

Lynch M, Sutula T (2000) Recurrent excitatory connectivity in the dentate gyrus of kindled and kainic acid-treated rats. J Neurophysiol 83:693-704.

Manent J, Demarque M, Jorquera I, Pellegrino C, Ben-Ari Y, Aniksztejn L, Represa A (2005) A noncanonical release of GABA and glutamate modulates neuronal migration. J Neurosci 25:4755-4765.

Mattson MP, Kumar KN, Wang H, Cheng B, Michaelis EK (1993) Basic FGF regulates the expression of a functional $71 \mathrm{kDa}$ NMDA receptor protein that mediates calcium influx and neurotoxicity in hippocampal neurons. J Neurosci 13:4575-4588.

Mazarati AM, Hohmann JG, Bacon A, Liu H, Sankar R, Steiner RA, Wynick D, Wasterlain CG (2000) Modulation of hippocampal excitability and seizures by galanin. J Neurosci 20:6276-6281.

Midzyanovskaya IS, Kuznetsova GD, Tuomisto L (2002) Brain histamine in the WAG/Rij rat, an animal model of absence epilepsy. Inflamm Res 51 [Suppl 1]:S49-S50.

Onodera K, Tuomisto L, Tacke U, Airaksinen M (1992) Strain differences in regional brain histamine levels between genetically epilepsy-prone and resistant rats. Methods Find Exp Clin Pharmacol 14:13-16.

Panula P, Yang HY, Costa E (1984) Histamine-containing neurons in the rat hypothalamus. Proc Natl Acad Sci USA 81:2572-2576.

Panula P, Airaksinen MS, Pirvola U, Kotilainen E (1990) A histaminecontaining neuronal system in human brain. Neuroscience 34:127-132.

Pitkanen A (2002) Efficacy of current antiepileptics to prevent neurodegeneration in epilepsy models. Epilepsy Res 50:141-160.

Routbort MJ, Bausch SB, McNamara JO (1999) Seizures, cell death, and mossy fiber sprouting in kainic acid-treated organotypic hippocampal cultures. Neuroscience 94:755-765.

Scherkl R, Hashem A, Frey HH (1991) Histamine in brain: its role in regulation of seizure susceptibility. Epilepsy Res 10:111-118.

Schmued LC, Hopkins KJ (2000) Fluoro-Jade B: a high affinity fluorescent marker for the localization of neuronal degeneration. Brain Res 874:123-130.

Schmued LC, Albertson C, Slikker Jr W (1997) Fluoro-Jade: a novel fluoro- 
chrome for the sensitive and reliable histochemical localization of neuronal degeneration. Brain Res 751:37-46.

Skaper SD, Facci L, Kee WJ, Strijbos PJ (2001) Potentiation by histamine of synaptically mediated excitotoxicity in cultured hippocampal neurones: a possible role for mast cells. J Neurochem 76:47-55.

Son LZ, Yanai K, Mobarakeh JI, Kuramasu A, Li ZY, Sakurai E, Hashimoto Y, Watanabe $\mathrm{T}$ (2001) Histamine $\mathrm{H}_{1}$ receptor-mediated inhibition of potassium-evoked release of 5-hydroxytryptamine from mouse forebrains. Behav Brain Res 124:113-120.

Sperk G, Furtinger S, Schwarzer C, Pirker S (2004) GABA and its receptors in epilepsy. Adv Exp Med Biol 548:92-103.

Stoppini L, Buchs PA, Muller D (1991) A simple method for organotypic cultures of nervous tissue. J Neurosci Methods 37:173-182.

Takeshita Y, Watanabe T, Sakata T, Munakata M, Ishibashi H, Akaike N (1998) Histamine modulates high-voltage-activated calcium channels in neurons dissociated from the rat tuberomammillary nucleus. Neuroscience $87: 797-805$.

Torrent A, Moreno-Delgado D, Gomez-Ramirez J, Rodriguez-Agudo D, Rodriguez-Caso C, Sanchez-Jimenez F, Blanco I, Ortiz J (2005) $\mathrm{H}_{3}$ autoreceptors modulate histamine synthesis through calcium/calmodulinand cAMP-dependent protein kinase pathways. Mol Pharmacol 67:195-203.

Traub RD, Borck C, Colling SB, Jefferys JGR (1996) On the structure of ictal events in vitro. Epilepsia 37:879-891.

Watanabe T, Taguchi Y, Hayashi H, Tanaka J, Shiosaka S, Tohyama M, Kubota H, Terano Y, Wada H (1983) Evidence for the presence of a histaminergic neuron system in the rat brain: an immunohistochemical analysis. Neurosci Lett 39:249-254.

West R, Zweig A, Shih N, Siegel M, Egan R, Clark M (1990) Identification of two $\mathrm{H}_{3}$-histamine receptor subtypes. Mol Pharmacol 38:610-613.

Yamamoto Y, Mochizuki T, Okakura-Mochizuki K, Uno A, Yamatodani A (1997) Thioperamide, a histamine $\mathrm{H}_{3}$ receptor antagonist, increases
GABA release from the rat hypothalamus. Methods Find Exp Clin Pharmacol 19:289-298.

Yamatodani A, Fukuda H, Wada H, Iwaeda T, Watanabe T (1985) Highperformance liquid chromatographic determination of plasma and brain histamine without previous purification of biological samples: cationexchange chromatography coupled with post-column derivatization fluorometry. J Chromatogr 344:115-123.

Yawata I, Tanaka K, Nakagawa Y, Watanabe Y, Murashima YL, Nakano K (2004) Role of histaminergic neurons in development of epileptic seizures in EL mice. Brain Res Mol Brain Res 132:13-17.

Yokoyama H (2001) The role of central histaminergic neuron system as an anticonvulsive mechanism in developing brain. Brain Dev 23:542-547.

Yokoyama H, Onodera K, Maeyama K, Yanai K, Iinuma K, Tuomisto L, Watanabe T (1992) Histamine levels and clonic convulsions of electrically-induced seizure in mice: the effects of alphafluoromethylhistidine and metoprine. Naunyn Schmiedebergs Arch Pharmacol 346:40-45.

Yokoyama H, Onodera K, Iinuma K, Watanabe T (1993) Effect of thioperamide, a histamine $\mathrm{H}_{3}$ receptor antagonist, on electrically induced convulsions in mice. Eur J Pharmacol 234:129-133.

Yokoyama H, Onodera K, Maeyama K, Sakurai E, Iinuma K, Leurs R, Timmerman H, Watanabe T (1994) Clobenpropit (VUF-9153), a new histamine $\mathrm{H}_{3}$ receptor antagonist, inhibits electrically induced convulsions in mice. Eur J Pharmacol 260:23-28.

Yokoyama H, Sato M, Iinuma K, Onodera K, Watanabe T (1996) Centrally acting histamine $\mathrm{H}_{1}$ antagonists promote the development of amygdala kindling in rats. Neurosci Lett 217:194-196.

Zhang L, Chen Z, Ren K, Leurs R, Chen J, Zhang W, Ye B, Wei E, Timmerman $\mathrm{H}$ (2003) Effects of clobenpropit on pentylenetetrazole-kindled seizures in rats. Eur J Pharmacol 482:169-175.

Zhang X, Cui SS, Wallace AE, Hannesson DK, Schmued LC, Saucier DM, Honer WG, Corcoran ME (2002) Relations between brain pathology and temporal lobe epilepsy. J Neurosci 22:6052-6061. 